\title{
Uncertain Henry's law constants compromise equilibrium partitioning calculations of atmospheric oxidation products
}

\author{
Chen Wang ${ }^{1}$, Tiange Yuan ${ }^{1}$, Stephen A. Wood ${ }^{1}$, Kai-Uwe Goss ${ }^{2,3}$, Jingyi Li ${ }^{4, a}$, Qi Ying ${ }^{4}$, and Frank Wania ${ }^{1}$ \\ ${ }^{1}$ Department of Physical and Environmental Sciences, University of Toronto Scarborough, 1265 Military Trail, \\ Toronto, ON, M1C 1A4, Canada \\ ${ }^{2}$ Department of Analytical Environmental Chemistry, Centre for Environmental Research UFZ Leipzig-Halle, \\ Permoserstraße 15, 04318 Leipzig, Germany \\ ${ }^{3}$ Institute of Chemistry, University of Halle-Wittenberg, Kurt-Mothes-Straße 2, 06120 Halle, Germany \\ ${ }^{4}$ Environmental and Water Resources Division, Zachry Department of Civil Engineering, \\ Texas A\&M University College Station, TX 77843-3136, USA \\ ${ }^{a}$ current address: School of Environmental Science and Engineering, Nanjing University of Information Science \& \\ Technology, 219 Ningliu Road, Nanjing 210044, China
}

Correspondence to: Frank Wania (frank.wania@utoronto.ca)

Received: 31 January 2017 - Discussion started: 14 February 2017

Revised: 18 May 2017 - Accepted: 19 May 2017 - Published: 22 June 2017

\begin{abstract}
Gas-particle partitioning governs the distribution, removal, and transport of organic compounds in the atmosphere and the formation of secondary organic aerosol (SOA). The large variety of atmospheric species and their wide range of properties make predicting this partitioning equilibrium challenging. Here we expand on earlier work and predict gas-organic and gas-aqueous phase partitioning coefficients for 3414 atmospherically relevant molecules using COSMOtherm, SPARC Performs Automated Reasoning in Chemistry (SPARC), and poly-parameter linear free-energy relationships. The Master Chemical Mechanism generated the structures by oxidizing primary emitted volatile organic compounds. Predictions for gas-organic phase partitioning coefficients $\left(K_{\mathrm{WIOM} / \mathrm{G}}\right)$ by different methods are on average within 1 order of magnitude of each other, irrespective of the numbers of functional groups, except for predictions by COSMOtherm and SPARC for compounds with more than three functional groups, which have a slightly higher discrepancy. Discrepancies between predictions of gas-aqueous partitioning $\left(K_{\mathrm{W} / \mathrm{G}}\right)$ are much larger and increase with the number of functional groups in the molecule. In particular, COSMOtherm often predicts much lower $K_{\mathrm{W} / \mathrm{G}}$ for highly functionalized compounds than the other methods. While the quantum-chemistry-based COSMOtherm accounts for the influence of intra-molecular interactions on conformation,
\end{abstract}

highly functionalized molecules likely fall outside of the applicability domain of the other techniques, which at least in part rely on empirical data for calibration. Further analysis suggests that atmospheric phase distribution calculations are sensitive to the partitioning coefficient estimation method, in particular to the estimated value of $K_{\mathrm{W} / \mathrm{G}}$. The large uncertainty in $K_{\mathrm{W} / \mathrm{G}}$ predictions for highly functionalized organic compounds needs to be resolved to improve the quantitative treatment of SOA formation.

\section{Introduction}

Volatile organic compounds (VOCs) emitted to the atmosphere are oxidized to form secondary products. These products tend to be more oxygenated, less volatile, and more water-soluble than their parent compounds, and thus have higher affinity for aerosol particles and aqueous droplets. Equilibrium partitioning coefficients are often needed to assess the distribution of these oxidized compounds among different phases in the atmosphere such as aerosol particles, fog droplets, and cloud droplets. In particular, the partitioning between gas and organic phase and between gas and aqueous phase is required for the evaluation of an organic compound's contribution to secondary organic aerosol (SOA) for- 
mation, its transport, removal, and lifetime. Experimentally determined partitioning coefficients are rarely available for the oxidation products of VOCs due to the difficulties in making the measurements and obtaining chemical standards. Furthermore, there are many thousand organic species in the atmosphere (Hallquist et al., 2009); the number is even higher when considering their isomers. Their gas-particle partitioning is therefore usually predicted. Reliable estimation methods for gas-organic and gas-aqueous partitioning should be applicable to a wide range of organic compounds, especially to multi-functional species generated during the multi-step atmospheric oxidation of precursor VOCs.

Current approaches for predicting partitioning into nonaqueous organic aerosol phases almost exclusively rely on predictions of vapor pressure. These predictions have large uncertainties; comparison among different vapor pressure prediction methods suggests increasing discrepancies with increasing numbers of functional groups in an organic compound (Valorso et al., 2011; Barley and McFiggans, 2010; McFiggans et al., 2010; Compernolle et al., 2011). This uncertainty matters, because it is the multi-functional oxidation products that can occur in either gas or condensed phases in the atmosphere. Instead of relying on predictions for vapor pressures, Wania et al. (2014) proposed using three alternative methods for direct gas-particle partitioning prediction: poly-parameter linear free-energy relationships (ppLFERs), the online calculator of SPARC Performs Automated Reasoning in Chemistry (SPARC), and the quantum-chemistrybased program COSMOtherm. Wania et al. (2014) found that partitioning coefficients predicted for the oxidation products of $n$-alkanes are within 1 order of magnitude, and mutual agreement does not deteriorate with increasing number of functional groups. Because of the relatively small number of oxidation products in that study, the reliability of these prediction methods for other organic compounds requires further evaluation.

While more experimental data exist for the Henry's law constant of atmospherically relevant compounds than gasorganic phase partitioning coefficients (Sander, 2015), data are not usually available for VOC oxidation products, which potentially have a higher affinity for atmospheric aqueous phases and a great atmospheric abundance. Currently available prediction methods for the air-water partitioning coefficient include the GROup contribution Method for Henry's law Estimate (GROMHE) (Raventos-Duran et al., 2010), SPARC (Hilal et al., 2008), HENRYWIN in EPI Suite (US EPA, 2012), and ppLFERs (Goss, 2006). Sander (2015) provides a more comprehensive list of websites as well as quantitative structure-property relationships for Henry's law constants. COSMOtherm can also predict gas-aqueous phase partitioning of organic compounds, including VOC oxidation products (Wania et al., 2015). Though many different methods are available for Henry's law constant prediction, they have not been systematically evaluated for a large set of organic compounds of atmospheric relevance. An excep- tion is the comparison of GROMHE, SPARC, and HENRYWIN predictions for 488 organic compounds bearing functional groups of atmospheric relevance (Raventos-Duran et al., 2010).

Even for the relatively simple molecules for which experimental evaluation data exist, these methods have considerable uncertainties. Raventos-Duran et al. (2010) reported root mean square errors (RMSEs) of $0.38,0.61$, and $0.73 \log$ unit for Henry's constants predicted by GROMHE, SPARC, and HENRYWIN, respectively. The ppLFER developed by Goss (2006) has a RMSE of $0.15 \log$ unit for the 217 compounds used for calibration. The error can be expected to be much larger for molecules that either are not part of the calibration (GROMHE, ppLFER) or are more complex. For a compound with multiple functional groups, Isaacman-VanWertz et al. (2016) found discrepancies in predicted Henry's law constant of several orders of magnitude. The method of Hodzic et al. (2014) of estimating the Henry's law constant for atmospheric oxidation products of different precursors also has uncertainties of several orders of magnitude.

The objective of this paper was to compare and evaluate gas-particle partitioning predictions for a large number of organic compounds of atmospheric interest using ppLFER (in combination with ABSOLV-predicted solute descriptors), SPARC, and COSMOtherm. While all three methods are able to estimate both gas-organic and gas-aqueous partitioning, they are based on different principles: ppLFERs are empirically calibrated multiple linear regressions, SPARC contains solvation models based on fundamental chemical structure theory (Hilal et al., 2004), and COSMOtherm combines quantum chemistry with statistical thermodynamics (Klamt and Eckert, 2000). This study thus expands earlier work (Wania et al., 2014) to a much larger number of compounds and to aqueous phase partitioning. As such, it includes quantumchemistry-based predictions for an unprecedented number of atmospherically relevant compounds.

\section{Method}

The Master Chemical Mechanism (MCM v3.2, http://mcm. leeds.ac.uk/MCM), a near-explicit chemical mechanism, was used to generate 3414 non-radical species through the multistep gas phase oxidation of 143 parent VOCs (methane +142 non-methane VOCs). Degradation of the parents VOCs through photolysis and reactions with $\mathrm{O}_{3}, \mathrm{OH}$, and $\mathrm{NO}_{3}$ are included in the MCM mechanism whenever such reactions are possible. The details about the studied compounds are given in the Supplement (Excel spreadsheet), including the compounds' MCM ID, SMILES (simplified molecular-input line-entry system), precursors (i.e., the parent VOC), molecular weight, molecular formula, elements, generation of oxidation, number and species of functional groups, $\mathrm{O}: \mathrm{C}$ ratio, and average carbon oxidation state $\left(\overline{\mathrm{OS}}_{\mathrm{C}}\right)$ (Kroll et al., 2011). 
Three prediction methods are used to estimate the equilibrium partitioning coefficients between a water-insoluble organic matter phase $(\mathrm{WIOM})$ and the gas phase $\left(K_{\mathrm{WIOM} / \mathrm{G}}\right)$ at $15^{\circ} \mathrm{C}$ in units of $\mathrm{m}^{3}$ (air) $\mathrm{m}^{-3}$ (WIOM) as well as the equilibrium partitioning coefficients between water and gas phase $\left(K_{\text {W/G }}\right)$ at $15^{\circ} \mathrm{C}$ in units of $\mathrm{m}^{3}$ (air) $\mathrm{m}^{-3}$ (water). The two partitioning coefficients are defined as

$K_{\mathrm{WIOM} / \mathrm{G}}=C_{\mathrm{WIOM}} / C_{\mathrm{G}}$,

$K_{\mathrm{W} / \mathrm{G}}=C_{\mathrm{W}} / C_{\mathrm{G}}$.

$C_{\mathrm{WIOM}}, C_{\mathrm{W}}$, and $C_{\mathrm{G}}\left(\mathrm{mol} \mathrm{m}^{-3}\right)$ are equilibrium concentrations of an organic compound in WIOM, water, and gas phase, respectively. Partitioning between gas and aqueous phase can be significantly influenced by the presence of inorganic salts (i.e., the salt effect) (Endo et al., 2012; Wang et al., 2016, 2014; Waxman et al., 2015), the hydration of carbonyls (Ip et al., 2009), and the dissociation of organic acids (Mouchel-Vallon et al., 2013), particularly in the aqueous phase of aerosols. However, in this study only the partitioning between gas and pure water, i.e., the Henry's law constant, is predicted, and no hydration, salt effect, or acid dissociation is considered. Conversion of partitioning coefficients $K_{\mathrm{W} / \mathrm{G}}$ to Henry's constant $\left(K_{\mathrm{H}}\right)$ in units of $\mathrm{M} \mathrm{atm}^{-1}$ or $K_{\mathrm{WIOM} / \mathrm{G}}$ to saturation concentration $\left(C^{*}, \mu \mathrm{g} \mathrm{m}^{-3}\right)$ is provided in the Supplement.

Wania et al. (2014) describe each prediction method in detail. In brief, ppLFERs are developed by performing a multi-linear regression of experimental $K$ values against compound-specific solute descriptors (Endo and Goss, 2014). These descriptors represent a solute's hydrogenbond acidity $(A)$, hydrogen-bond basicity $(B)$, dipolarity/polarizability $(S)$, McGowan volume $\left(\mathrm{cm}^{3} \mathrm{~mol}^{-1}\right)$ divided by $100(V)$, excess molar refraction $(E)$, and logarithmic hexadecane-air partitioning constant at $25^{\circ} \mathrm{C}(L)$. In this study, solute descriptors for the 3414 compounds were predicted with ABSOLV (ACD/Labs, Advanced Chemistry Development, Inc., Toronto, Canada). The regression coefficients in ppLFERs are denoted by $a, b, s, v, e$, and $l ; c$ is the regression constant. The ppLFER for air-water partitioning was taken from Goss (2006):

$\log K_{\mathrm{W} / \mathrm{G}}=c+a A+b B+s S+v V+e E ;$

whereas ppLFERs for four different organic aerosol were taken from Arp et al. (2008):

$\log K_{\mathrm{Aerosol} / \mathrm{G}}=c+a A+b B+s S+v V+l L$.

As described in Wania et al. (2014), the average of the four $K_{\text {Aerosol/G }}$ was compared with the $K_{\text {WIOM/G }}$ predicted by the other two methods. SPARC is a commercial web-based calculator for prediction of physical chemical properties from molecular structure developed by the US Environmental Protection Agency (Hilal et al., 2004). The predictions of $K_{\mathrm{W} / \mathrm{G}}$ and $K_{\mathrm{WIOM} / \mathrm{G}}$ are based on solvation models in SPARC that describe the intermolecular interaction between different molecules (solute and solvent), including dispersion, induction, dipole-dipole, and H-bonding interactions, which are developed and calibrated with experimental data (Hilal et al., 2008). For the calculations of $K_{\mathrm{WIOM} / \mathrm{G}}$ by SPARC and COSMOtherm, the phase WIOM is represented by the surrogate structure "B" as proposed by Kalberer et al. (2004) and adopted previously by Arp and Goss (2009) and Wania et al. (2014). SPARC calculations were carried out using the online calculator (http://archemcalc.com/sparc-web/calc), with SMILES strings as input. COSMOtherm predicts a large variety of properties based on COSMO-RS (conductorlike screening model for real solvents) theory, which uses quantum-chemical calculations and statistical thermodynamics (Klamt and Eckert, 2000; Klamt, 2005). First, TURBOMOLE (version 6.6, 2014, University of Karlsruhe \& Forschungszentrum Karlsruhe GmbH, 1989-2007, TURBOMOLE GmbH, since 2007 available from http://www. turbomole.com) optimizes the geometry of the molecules of interest by quantum-chemical calculations at the BP-TZVP level. COSMOconf (version 3.0, COSMOlogic) then selects a maximum of 10 of the lowest-energy conformers for each calculated molecule and generates COSMO files. Calculations with TURBOMOLE and COSMOconf were performed on the General Purpose Cluster (GPC) supercomputer at the SciNet HPC Consortium at the University of Toronto (Loken et al., 2010). Finally, COSMOtherm (version C30_1501 with BP_TZVP_C30_1501 parameterization, COSMOlogic GmbH \& Co. KG, Leverkusen, Germany, 2015) calculates partitioning coefficients from the selected COSMO files at $15^{\circ} \mathrm{C}$.

In order to compare different predictions numerically, we calculated the mean difference (MD) and the mean absolute difference (MAD) for each pair of $K_{\mathrm{WIOM} / \mathrm{G}}$ or $K_{\mathrm{W} / \mathrm{G}}$ sets:

$$
\begin{aligned}
& \mathrm{MD}_{X Y}=\frac{1}{n} \sum_{i}\left(\log _{10} K_{i, \mathrm{CP} / \mathrm{G} X}-\log _{10} K_{i, \mathrm{CP} / \mathrm{G} Y}\right), \\
& \operatorname{MAD}_{X Y}=\frac{1}{n} \sum_{i}\left|\log _{10} K_{i, \mathrm{CP} / \mathrm{G} X}-\log _{10} K_{i, \mathrm{CP} / \mathrm{G} Y}\right| \text {, }
\end{aligned}
$$

where CP ("condensed phase") stands for either WIOM or water, and $X$ and $Y$ represent two prediction techniques.

\section{Results}

\subsection{The range of estimated partitioning coefficients}

Partitioning coefficients predicted for each compound with different methods are given in an Excel spreadsheet in the Supplement. All three methods predicted the $\log K_{\text {WIOM/G }}$ for these organic compounds to range from approximately 0 to 15 (Fig. 1a-c). Hodzic et al. (2014) predicted a log $K_{\text {WIOM/G }}$ in the range of approximately $0-20$ at $25^{\circ} \mathrm{C}$ (see conversion between $C^{*}$ and $K_{\mathrm{WIOM} / \mathrm{G}}$ in the Supplement) for 

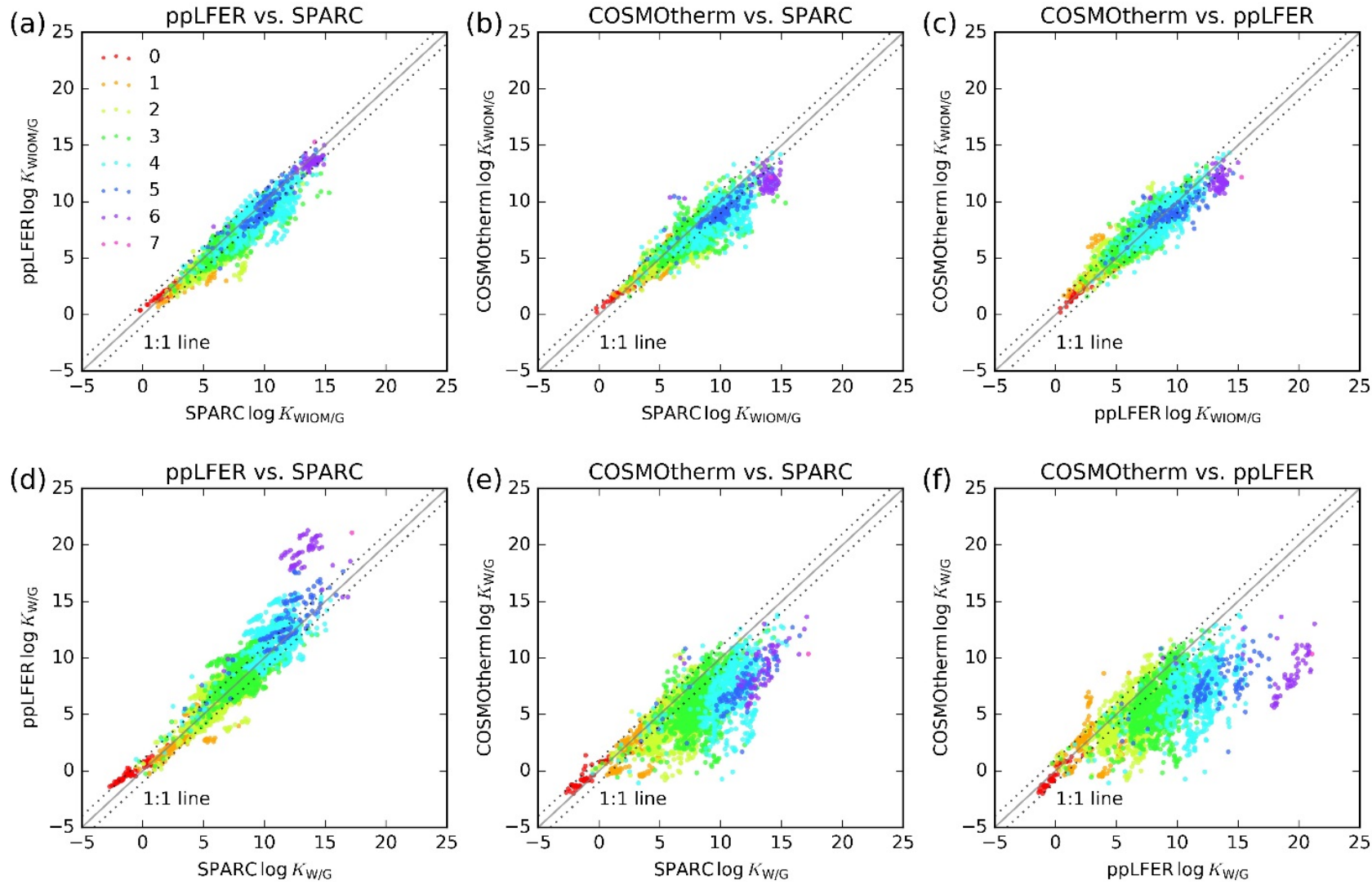

Figure 1. Comparison of the $K_{\mathrm{WIOM} / \mathrm{G}}$ (upper panel) and $K_{\mathrm{W} / \mathrm{G}}$ (lower panel) predicted using COSMOtherm, SPARC, and ABSOLVppLFERs. The differently colored dots indicate the number of functional groups in the molecules. The solid line indicates a $1: 1$ agreement. The dotted lines indicate a deviation by $\pm 1 \log$ unit.

oxidation products of different VOCs (including $n$-alkanes, benzene, toluene, xylene, isoprene, and terpenes); i.e., their data set included higher $K_{\text {WIOM/G }}$ values (indicating generally lower volatility) than those generated here, even though $K_{\text {WIOM/G }}$ values are lower at higher temperature.

The $\log K_{\mathrm{W} / \mathrm{G}}$ range predicted for the studied compounds by the three methods is more variable (Fig. 1d-f), with the ABSOLV-ppLFER predictions covering a wider range $(-1.4$ to 21.3) than either SPARC ( -2.7 to 17.2) or COSMOtherm ( -2 to 13.8). Hodzic et al. (2014) predicted a $\log K_{\mathrm{W} / \mathrm{G}}$ in the range of -2.6 and 17.4 at $25^{\circ} \mathrm{C}$ (see conversion to $K_{\mathrm{H}}$ in the Supplement). The wider range of the ABSOLV-ppLFER predictions is due to much higher predicted $K_{\mathrm{W} / \mathrm{G}}$ values for compounds with the highest affinity for the aqueous phase.

\subsection{Comparison between different prediction methods}

The discrepancies between different predictions (MAD and $\mathrm{MD})$ are given in Table 1. Figure S1 in the Supplement illustrates the frequency of the discrepancies between different pairs of predicted $\log K_{\mathrm{WIMO} / \mathrm{G}}$ and $\log K_{\mathrm{W} / \mathrm{G}}$ values. This discrepancy only indicates the agreement between any two predictions with little indication of the accuracy of the prediction, for reasons discussed later. The agreement between the $K_{\text {WIOM/G }}$ predictions by COSMOtherm, SPARC, and ABSOLV-ppLFER was reasonable (Fig. $1 \mathrm{a}-\mathrm{c}$ ). In particular, the MAD between $K_{\mathrm{WIOM} / \mathrm{G}}$ predictions is less than $1 \log$ unit (Table 1) and therefore similar to what had been previously found for a much smaller set of $n$-alkane oxidation products (Wania et al., 2014). The $K_{\text {WIOM/G }}$ values predicted by SPARC tend to be higher than those predicted by COSMOtherm and ABSOLV-ppLFER (MD of -0.64 and $-0.79 \log$ unit, respectively), whereas the latter two predictions have a slightly better agreement, with a MD of $0.15 \log$ unit (Fig. 1c and Table 1). Overall, the agreement in the $K_{\mathrm{WIOM} / \mathrm{G}}$ predicted with these three methods, which are based on very different theoretical foundations, is much better than that between different vapor pressure estimation methods commonly used for gas-particle partitioning calculations (Valorso et al., 2011).

The $K_{\text {W/G }}$ predicted by ABSOLV-ppLFER and SPARC differ from COSMOtherm predictions substantially, on average by more than 2 orders of magnitude. In Fig. 1e and $\mathrm{f}$, predictions are more scattered (indicating a larger MAD), and most markers are located below the $1: 1$ line, indicating that $K_{\mathrm{W} / \mathrm{G}}$ predicted by COSMOtherm are mostly lower 
Table 1. Mean absolute differences (MADs) and mean differences (MDs) between SPARC, ABSOLV-ppLFER, and COSMOtherm predictions for compounds with different numbers of functional groups.

\begin{tabular}{|c|c|c|c|c|c|c|c|c|c|c|}
\hline \multirow{2}{*}{\multicolumn{3}{|c|}{$\begin{array}{l}\text { Number of functional groups } \\
\text { Number of compounds }\end{array}$}} & 0 & 1 & 2 & 3 & 4 & 5 & $>5$ & All \\
\hline & & & 63 & 372 & 1179 & 1064 & 565 & 111 & 60 & 3414 \\
\hline \multirow[t]{6}{*}{$\log K_{\mathrm{WIOM} / \mathrm{G}}$} & \multirow[t]{2}{*}{ ppLFER vs. SPARC } & MAD & 0.24 & 0.70 & 0.95 & 0.93 & 1.08 & 0.75 & 0.54 & 0.91 \\
\hline & & MD & 0.05 & -0.70 & -0.91 & -0.81 & -0.83 & -0.24 & -0.30 & -0.79 \\
\hline & \multirow[t]{2}{*}{ COSMOtherm vs. SPARC } & MAD & 0.36 & 0.48 & 0.80 & 0.94 & 1.42 & 1.22 & 2.11 & 0.94 \\
\hline & & MD & 0.29 & -0.19 & -0.55 & -0.57 & -1.21 & -0.78 & -1.83 & -0.64 \\
\hline & \multirow[t]{2}{*}{ COSMOtherm vs. ppLFER } & MAD & 0.32 & 0.67 & 0.63 & 0.74 & 0.89 & 0.93 & 1.72 & 0.73 \\
\hline & & MD & 0.24 & 0.51 & 0.36 & 0.24 & -0.38 & -0.54 & -1.53 & 0.15 \\
\hline \multirow[t]{6}{*}{$\log K_{\mathrm{W} / \mathrm{G}}$} & \multirow[t]{2}{*}{ ppLFER vs. SPARC } & MAD & 0.75 & 0.57 & 0.84 & 1.08 & 1.48 & 1.53 & 5.78 & 1.10 \\
\hline & & MD & 0.74 & -0.09 & -0.15 & 0.38 & 0.87 & 1.45 & 5.76 & 0.36 \\
\hline & \multirow[t]{2}{*}{ COSMOtherm vs. SPARC } & MAD & 0.51 & 0.86 & 1.61 & 2.31 & 3.78 & 4.34 & 4.55 & 2.23 \\
\hline & & MD & 0.48 & -0.59 & -1.44 & -2.18 & -3.74 & -4.04 & -4.36 & -2.06 \\
\hline & \multirow[t]{2}{*}{ COSMOtherm vs. ppLFER } & MAD & 0.40 & 1.16 & 1.64 & 2.63 & 4.62 & 5.55 & 10.09 & 2.64 \\
\hline & & MD & -0.26 & -0.50 & -1.29 & -2.56 & -4.61 & -5.50 & -10.05 & -2.42 \\
\hline
\end{tabular}

than those predicted by SPARC and ABSOLV-ppLFER, with a MD of -2.06 and $-2.42 \log$ units, respectively. These discrepancies tend to increase with the $K_{\mathrm{W} / \mathrm{G}}$. RaventosDuran et al. (2010) also showed that the reliability of $K_{\mathrm{W} / \mathrm{G}}$ estimates made by GROMHE, SPARC, and HENRYWIN decreases with increasing affinity for the aqueous phase. $K_{\mathrm{W} / \mathrm{G}}$ predictions by SPARC and ABSOLVppLFER are more consistent (with a MAD around 1 log unit; see Fig. 1d). The largest discrepancies between ABSOLVppLFER and SPARC (and also between ABSOLV-ppLFER and COSMOtherm) occur for compounds with the highest $K_{\text {W/G }}$ as predicted by ABSOLV-ppLFER (purple markers in Fig. 1d and f). Further analysis indicates that these compounds have the largest number of functional groups $(\geq 6)$ and oxygen (9-12 oxygen) in the molecule; this will be discussed in detail below.

\subsection{Dependence of partitioning coefficients on attributes of the compounds}

The equilibrium partitioning coefficients depend on molecular attributes. Here we explored this dependency on the number of functional groups, molecular mass, generation of oxidation, number of oxygens, and $\mathrm{O}: \mathrm{C}$ ratio.

Previous work observed that discrepancies between vapor pressure predictions by different methods increased with the number of functional groups in atmospherically relevant organic compounds (Valorso et al., 2011; Barley and McFiggans, 2010; Compernolle et al., 2011). For instance, the MAD between different vapor pressure predictions increased from 0.47 to $3.6 \mathrm{log}$ units when the number of functional groups in the molecules increased from one to more than three (Valorso et al., 2011). In order to explore if the partitioning coefficients predicted with SPARC, ABSOLV-ppLFER, and COSMOtherm show the same dependence on the number of functional groups, we counted the number of hydroxyl (ROH), aldehyde (RCHO), ketone (RCOR'), carboxylic acid (RCOOH), ester (RCOOR'), ether (ROR'), peracid (RCOOOH), peroxide (ROOH, ROOR'), nitrate $\left(\mathrm{NO}_{3}\right)$, peroxyacyl nitrate (PAN), nitro $\left(\mathrm{NO}_{2}\right)$ groups, halogen $(\mathrm{Cl}, \mathrm{Br})$, and sulfur $(\mathrm{S})$ in the 3414 molecules. About two-thirds (2243) of the compounds contain two or three functional groups (Table 1). A total of 736 compounds contain more than three functional groups, and the rest contain just one or no functional group. In Fig. 1 the compounds are colored according to the number of functional groups in a molecule, and Table 1 lists the MAD and MD between predictions based on the number of functional groups. The predicted partitioning coefficients (both $K_{\text {WIOM/G }}$ and $K_{\text {W/G }}$ ) generally increase with the number of functional groups (Figs. 1 and S2). Compounds with no functional groups are the precursor compounds, which generally have a smaller discrepancy among different prediction methods.

The box plots in Fig. 2 show the difference in SPARC, ABSOLV-ppLFER, and COSMOtherm predictions for compounds having different number of functional groups. The mean absolute difference in predicted $\log K_{\mathrm{WIOM} / \mathrm{G}}$ is mostly (and on average) smaller than $1 \mathrm{log}$ unit for compounds with up to seven functional groups (Table 1). There is a slightly larger discrepancy in the predicted $\log K_{\mathrm{WIOM} / \mathrm{G}} \mathrm{val}-$ ues for compounds with more than three functional groups. The agreement among different methods does not deteriorate as much with increasing number of functional groups as that among vapor pressure predictions. The largest MADs of 1.72 and 2.11 between COSMOtherm and ABSOLVppLFER and between COSMOtherm and SPARC, respectively, for compounds with more than five functional groups (Table 1) are still much lower than discrepancies reported between different vapor pressure prediction methods (Valorso et al., 2011). 

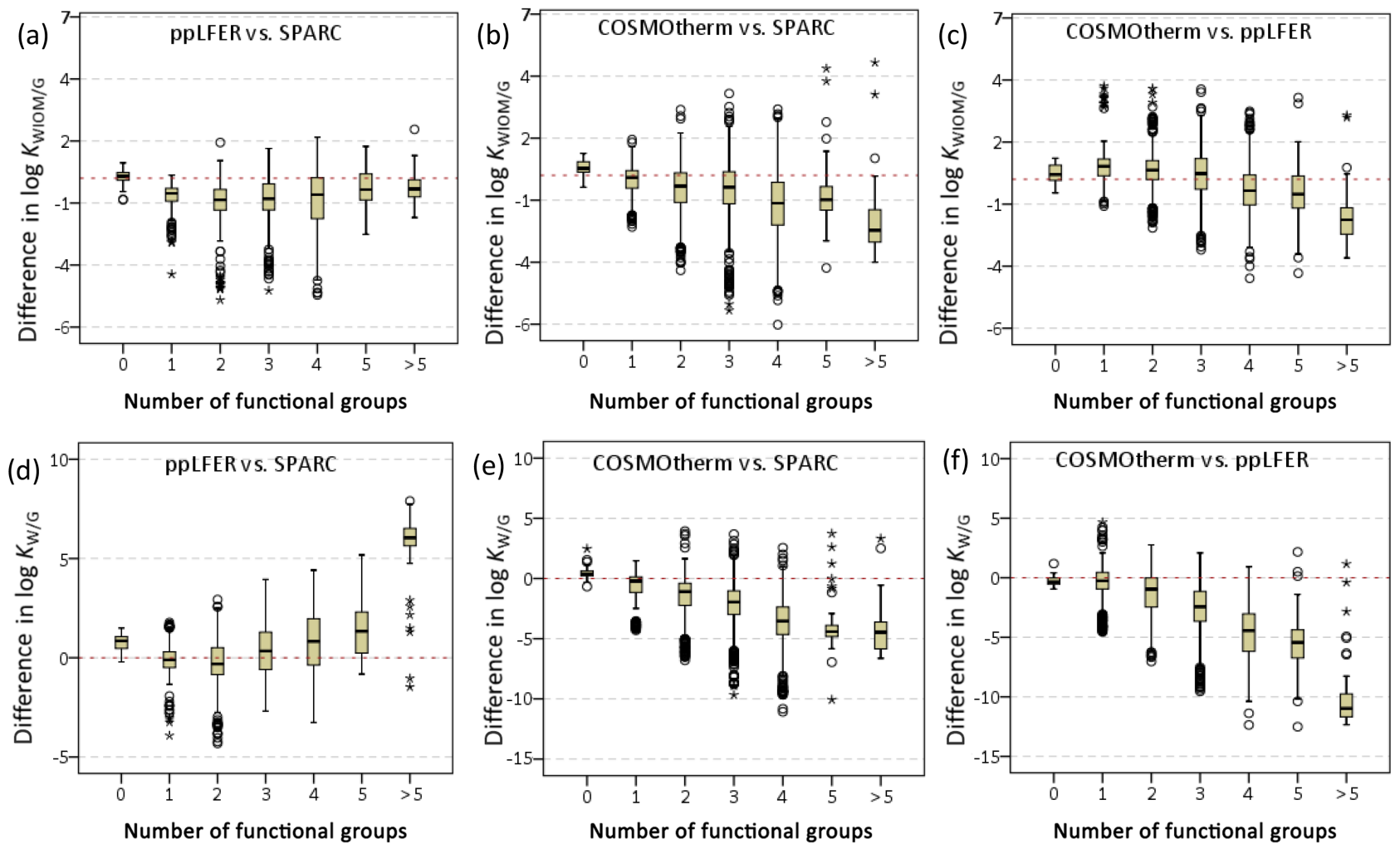

Figure 2. Box plot of difference in SPARC, ABSOLV-ppLFER, and COSMOtherm predictions for compounds with different number of functional groups. The line inside each box shows the median difference for $\log K_{\mathrm{WIOM} / \mathrm{G}}$ or $\log K_{\mathrm{W} / \mathrm{G}}$ for different categories of compounds. The marker circle and star indicate possible outliers and extreme values, respectively. Note the different scales for different panels.

Different from the predictions for $K_{\mathrm{WIOM} / \mathrm{G}}$, the discrepancy between COSMOtherm and SPARC and between COSMOtherm and ABSOLV-ppLFER in the predicted $K_{\text {W/G }}$ increases significantly with the number of functional groups (Figs. 1 and 2), from less than 1 order of magnitude for compounds with no functional groups to up to 5 orders of magnitude for compounds with more than three functional groups (Table 1). In addition, the MDs in Table 1 and Fig. 2 indicate that the discrepancies are almost always in one specific direction, i.e., a lower value of $K_{\text {W/G }}$ estimated by COSMOtherm. This is evidenced by the almost identical absolute values of MAD and MD between COSMOtherm and ABSOLV-ppLFER and between COSMOtherm and SPARC for compounds with more than three functional groups (Table 1). The uncertainty of the SPARC, ABSOLV-ppLFER, and COSMOtherm predictions of $K_{\mathrm{W} / \mathrm{G}}$ tends to increase with the number of functional groups. Clearly, the reliability of $K_{\text {W/G }}$ estimates for multi-functional compounds needs further assessment.

It is also possible to explore the dependence of the prediction discrepancy on other molecular attributes, such as molecular mass (Figs. S3 and S4), the number of oxygen in the molecule (Figs. S5 and S6), the O:C ratio (Fig. S7), the number of oxidation steps a molecular has undergone (ox- idation generation, Fig. S8), or the number of occurrences of a specific type of functional group (e.g., hydroxyl) in a molecule (Fig. S9). The prediction discrepancies become larger with an increase in each of these parameters, especially for $K_{\mathrm{W} / \mathrm{G}}$. This is not surprising as these molecular attributes all tend to be highly correlated; i.e., with each oxidation step a molecule becomes more oxygenated, has a large molar mass, a larger number of oxygen, a higher $\mathrm{O}: \mathrm{C}$ ratio, and a larger number of functional groups.

\section{Discussion}

We believe there are primarily two factors that are contributing to errors in the prediction of $K_{\mathrm{CP} / \mathrm{G}}$ for the SOA compounds. One is the lack of experimental data for compounds that are similar to the SOA compounds, which implies that prediction methods relying on calibration with experimental data are being used outside their applicability domain. The other is the failure of some prediction methods to account for the various conformations that compounds with multiple functional groups can undergo due to extensive intramolecular interaction (mostly internal hydrogen bonding; see Fig. S10 for example). The two factors are related: in some instances a prediction method cannot account for such con- 
formations precisely because the calibration data set does not contain compounds that undergo such intra-molecular interactions.

SPARC relies to some extent on calibrations with empirical data. While the experimental data underlying SPARC have not been disclosed, it is highly unlikely that they include multi-functional compounds of atmospheric relevance (e.g., compounds containing multiple functional groups, including peroxides, peroxy acids, etc.), simply because such empirical data do not exist. It is therefore safe to assume that many of the 3414 SOA compounds will fall outside of the domain of applicability of SPARC. It is also likely that SPARC can only account for intra-molecular interactions and conformations to a limited extent, if at all.

In the case of ppLFER, there are actually two predictions that rely on calibration with empirical data: the prediction of solute descriptors and the prediction of $K_{\mathrm{CP} / \mathrm{G}}$. The solute descriptors are predicted with ABSOLV, because experimentally measured descriptors are unavailable for multifunctional atmospheric oxidation products. ABSOLV relies on a group contribution approach (Platts et al., 1999) complemented by some other, undisclosed procedures that make use of experimental partitioning coefficients between various phases (ACD/Labs, 2016). Again, those experimental data do not comprise compounds structurally similar to the multifunctional atmospheric oxidation products considered here. As a group contribution method, which adds up the contributions of different functional groups to a compound's property, ABSOLV therefore cannot, or only to a limited extent, consider the interactions between different functional groups in a molecule.

Ideally, when supplied with well-characterized solute descriptors, ppLFERs should be able to consider the influence of both intra-molecular interactions and the interactions a molecule has with its surroundings, i.e., the involved partitioning phases. Even if a molecule has different conformations in different phases, i.e., if the solute descriptors for a compound are phase dependent, it is possible to derive well-calibrated "average" descriptors to use in a ppLFER (Niederer and Goss, 2008). However ABSOLV cannot correctly predict such "average" descriptors, and our ppLFER predictions therefore cannot account for the influence of conformations.

In the case of the actual ppLFER prediction of $K_{\mathrm{W} / \mathrm{G}}$ and $K_{\mathrm{WIOM} / \mathrm{G}}$, the empirical calibration data sets are public (Goss, 2006; Arp et al., 2008) and do not comprise compounds that are representative of the 3414 SOA compounds in terms of the number of functional groups per molecule or the range of $K$ values. For instance, the $\log K_{\mathrm{W} / \mathrm{G}}$ of the 217 compounds Goss (2006) used for the development of a ppLFER ranged from -2.4 to 7.4 ; i.e., the highest $K_{\mathrm{W} / \mathrm{G}}$ predicted here is almost 14 orders of magnitude higher than the highest $K_{\mathrm{W} / \mathrm{G}}$ included in the calibration. Similarly, Arp and Goss (2009) developed the ppLFERs for atmospheric aerosol from an empirical data set of 50-59 chemicals, whose $\log K_{\mathrm{WIOM} / \mathrm{G}}$ ranged from approximately 2 to 7 . The highest $K_{\mathrm{WIOM} / \mathrm{G}}$ predicted here is 8 orders of magnitude higher. Predictions for compounds outside of the calibration domain may introduce large errors, and the high $K_{\mathrm{W} / \mathrm{G}}$ and $K_{\mathrm{WIOM} / \mathrm{G}}$ values estimated by ppLFER can thus be expected to be highly uncertain. Overall, however, we expect the uncertainty of the ABSOLV-predicted solute descriptors to be larger than the uncertainty introduced by the ppLFER equation, especially for the relatively well-calibrated water-gas phase partition system. While the use of measured solute descriptors therefore would likely greatly improve the ppLFER prediction (Endo and Goss, 2014), those are unlikely to become available for atmospheric oxidation products.

In contrast to the other methods, COSMOtherm relies only in a very fundamental way on some empirical calibrations (and these calibrations are not specific for specific compound classes or partition systems), and it considers intra-molecular interactions and the different conformations of a molecule. As such, COSMOtherm is not constrained by the limitations the other methods face, namely the lack of suitable calibration data, which necessitates extreme extrapolations and predictions beyond the applicability domain, and the failure to account for the effect of intra-molecular interactions and conformations on the interactions with condensed phases.

Because intra-molecular interactions are likely to reduce the potential of a compound to interact with condensed phases (i.e., the organic and aqueous phase), ignoring them can be expected to lead to overestimated partitioning coefficients $K_{\mathrm{CP} / \mathrm{G}}$ and to underestimated vapor pressures $\left(P_{L}\right)$ and $C^{*}$, i.e., underestimating the volatility of the organic compounds. This is consistent with COSMOtherm-predicted $K_{\mathrm{WIOM} / \mathrm{G}}$ and $K_{\mathrm{W} / \mathrm{G}}$ values for multi-functional compounds that are lower than the SPARC and ABSOLV-ppLFER predictions (i.e., $\mathrm{MD}<0$ in Table 1), because the latter do not account for the influence of intra-molecular interactions. Kurtén et al. (2016) similarly found that COSMOthermpredicted saturation vapor pressures for most of the more highly oxidized monomers were significantly higher (up to 8 orders of magnitude) than those predicted by group contribution methods. The wider range on the higher end of the $\log C^{*}$ values estimated by Hodzic et al. (2014) is possibly due to the large uncertainties associated with vapor pressure estimation (likely underestimation) for low-volatility compounds. Valorso et al. (2011) also found group contribution methods to underestimate the saturation vapor pressure of multi-functional species.

Compared to $K_{\mathrm{WIOM} / \mathrm{G}}, P_{L}$, and $C^{*}$, ignoring intramolecular interaction is likely even more problematic in the case of $K_{\mathrm{W} / \mathrm{G}}$ prediction. Intra-molecular interactions mostly affect the ability of the molecule to undergo $\mathrm{H}$ bonding with solvent molecules. The system constants describing $\mathrm{H}$-bond interactions ( $a$ and $b$ ) are larger in the ppLFER equations for $K_{\mathrm{W} / \mathrm{G}}$ than in the one for $K_{\mathrm{WIOM} / \mathrm{G}}$ (Arp et al., 2008; Goss, 2006), indicating a stronger effect of $\mathrm{H}$ bonds on water-gas partitioning than WIOM-gas partitioning. This likely is the 
reason why the COSMOtherm-predicted $K_{\mathrm{W} / \mathrm{G}}$ are so much lower than the $K_{\mathrm{W} / \mathrm{G}}$ predicted by the other two methods, whereas the difference is much smaller for the $K_{\mathrm{WIOM} / \mathrm{G}}(\mathrm{Ta}-$ ble 1). It likely also explains why the discrepancies among the predicted $K_{\mathrm{W} / \mathrm{G}}$ increase with the number of functional groups. It is more difficult to predict $K_{\mathrm{W} / \mathrm{G}}$ than $K_{\mathrm{WIOM} / \mathrm{G}}$, because the free-energy cost of cavity formation in water is influenced more strongly by $\mathrm{H}$ bonding and therefore much more variable than in WIOM. Certainly, the activity coefficient in water $\left(\gamma_{\mathrm{W}}\right)$ is much more variable than the activity coefficient in WIOM $\left(\gamma_{\text {WIOM }}\right)$ for the investigated substances. $\log \gamma$ WIOM predicted by COSMOtherm at $15^{\circ} \mathrm{C}$ varies from -3.8 to 1.8 (with an average of 0.04 and a standard deviation of 0.5 , indicating a $\gamma_{\text {WIOM }}$ close to unity; $94 \%$ of the compounds have a $\log \gamma$ WIOM between -1 and 1 ), whereas $\gamma_{\mathrm{W}}$ ranges from -2.3 to 8.9 (with an average of 2.7 and a standard deviation of 1.4) (Supplement Excel spreadsheet and Fig. S11).

In the absence of experimental data for multi-functional SOA compounds, we do not know whether COSMOthermpredicted $K_{\text {W/G }}$ and $K_{\text {WIOM/G }}$ values are any better than the other predictions. For example, two earlier studies suggested that COSMOtherm might be overestimating vapor pressures of multi-functional oxygen-containing compounds (Kurtén et al., 2016; Schröder et al., 2016). However, we can infer the following:

- The fact that COSMOtherm on the one hand and ABSOLV-ppLFERs and SPARC on the other hand predict $K_{\mathrm{WIOM} / \mathrm{G}}$ that are on average within 1 order of magnitude for all studied compounds, and less than 2 orders of magnitude for highly oxygenated multi-functional organic compounds, lends credibility to all three predictions and suggests that partly ignoring intra-molecular interactions and extrapolating beyond the applicability domain incurs only limited errors in the $K_{\mathrm{WIOM} / \mathrm{G}}$ prediction of ABSOLV-ppLFERs and SPARC. In addition, COSMOtherm and SPARC use a single surrogate molecule to represent the WIOM phase, while ppLFERs were calibrated from atmospheric aerosols. The agreement among different methods suggests that the surrogate suitably represents the solvation properties of organic aerosol.

- The generally better agreement between $K_{\mathrm{W} / \mathrm{G}}$ values predicted by ABSOLV-ppLFER and SPARC (Fig. 1d) should not be seen as an indication that these methods are better at predicting $K_{\mathrm{W} / \mathrm{G}}$. In fact, the lower $K_{\text {W/G }}$ values predicted by COSMOtherm have a higher chance of being correct than the $K_{\mathrm{W} / \mathrm{G}}$ values predicted by ABSOLV-ppLFER and SPARC.

While ABSOLV-ppLFERs, SPARC, and the group contribution methods currently used in the atmospheric chemistry community are much more easily implemented for the large number of compounds implicated in SOA formation, the cur- rent study demonstrates that the expertise and time required to perform quantum-chemical calculations for atmospherically relevant molecules should constitute but a minor impediment to a wider adoption of COSMOtherm predictions. Here, we are not only compiling all the predictions we have made in the Supplement file; we are also making available the COSMO files (see "Data availability" section for details), whose generation is the major time- and CPU-demanding step in the use of COSMOtherm.

\section{Atmospheric implications}

The phase distribution of an organic compound in the atmosphere depends on its partitioning coefficients. The twodimensional partitioning space defined by $\log K_{\text {W/G }}$ and $\log$ $K_{\text {WIOM/G }}$ introduced recently (Wania et al., 2015) is used here to illustrate the difference in the equilibrium phase distribution of these compounds in the atmosphere that arises from using partitioning coefficients estimated by different methods (Fig. 3). A detailed description of partitioning space has been provided by Wania et al. (2015); a brief explanation is given in the Supplement (Fig. S12). Briefly, the blue solid lines between the differently colored fields indicate partitioning property combinations that lead to equal distributions between two phases in a phase-separated aerosol scenario, with a liquid water content (LWC) of $10 \mu \mathrm{g} \mathrm{m}^{-3}$ and organic matter loading $(\mathrm{OM})$ of $10 \mathrm{\mu g} \mathrm{m}^{-3}$. The blue dotted lines represent a cloud scenario where LWC is $0.3 \mathrm{~g} \mathrm{~m}^{-3}$ and $\mathrm{OM}$ is $10 \mu \mathrm{g} \mathrm{m}^{-3}$. Figures S13 and S14 in the Supplement show an aerosol scenario without an aqueous phase and a cloud scenario without a separated organic phase because all of the $\mathrm{OM}$ is dissolved in the aqueous phase (see also Fig. S12c and d). Compounds are located in the partitioning space based on their estimated partitioning coefficients ( $K_{\mathrm{WIOM} / \mathrm{G}}$ and $\left.K_{\mathrm{W} / \mathrm{G}}\right)$. Compounds on the boundary lines have $50 \%$ in either of the two phases on both sides of the boundary and are thus most sensitive to uncertain partitioning properties. On the other hand, for substances that fall far from the boundary lines indicating a phase transition (e.g., volatile compounds with two or less functional groups), even relatively large uncertainties in the partitioning coefficients could be tolerated, because they are inconsequential.

When plotted in the chemical partition space, the 3414 chemicals occupy more or less the same region as the much smaller set of SOA compounds investigated earlier (Wania et al., 2015). When using predictions by COSMOtherm, the SOA compounds cover a relatively smaller region as compared to ABSOLV-ppLFER and SPARC. With increasing number of functional groups (Fig. 3) or molecular weight (Fig. S15), an increasing fraction of these compounds partitions into the condensed phases, i.e., WIOM or water. In general, compounds with water or WIOM as the dominant phase usually are multifunctional; i.e., they contain more than two functional 

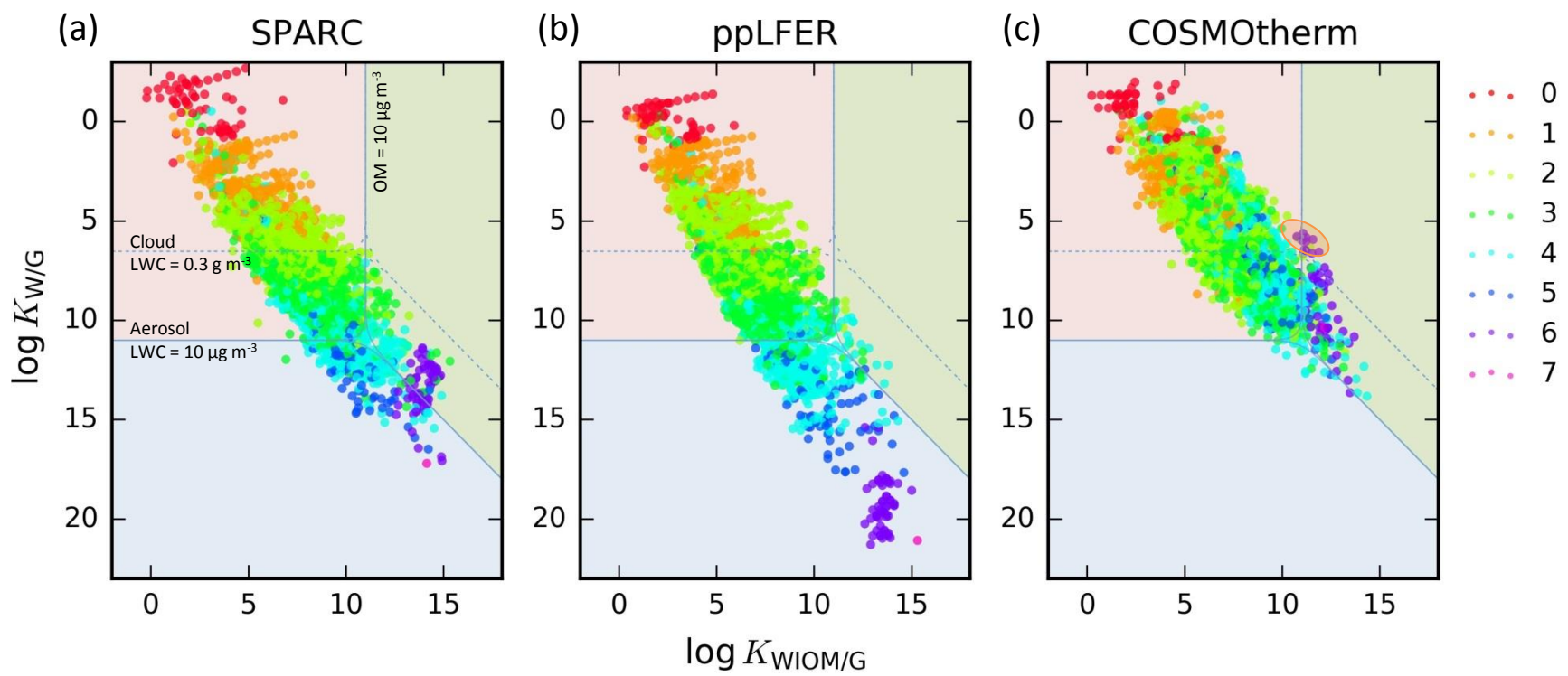

Figure 3. Partitioning space plot, showing in pink, blue, and green the combinations of partitioning properties that lead to dominant equilibrium partitioning to the gas, aqueous, and WIOM phases, respectively. The blue solid and dotted lines are boundaries for an aerosol scenario (LWC: $10 \mu \mathrm{g} \mathrm{m}^{-3}$; OM: $10 \mu \mathrm{g} \mathrm{m}^{-3}$ ) and a cloud scenario (LWC: $0.3 \mathrm{~g} \mathrm{~m}^{-3}$; OM: $10 \mu \mathrm{g} \mathrm{m}^{-3}$ ), respectively. The differently colored dots indicate the number of functional groups in the molecules.

groups. According to Fig. S15, compounds with predominant partitioning into WIOM usually have a molar mass in excess of $200 \mathrm{~g} \mathrm{~mol}^{-1}$, while some compounds with molar mass less than $200 \mathrm{~g} \mathrm{~mol}^{-1}$ prefer the aqueous phase. Other than the water content and WIOM loadings illustrated in Fig. 3, in reality a compound's atmospheric phase distribution depends on other factors such as the organic matter composition, salt content, $\mathrm{pH}$, and temperature (Wania et al., 2015; Wang et al., 2015).

Comparing the different panels of Fig. 3 reveals that the atmospheric equilibrium phase distribution of SOA compounds can be very different depending on which method is used for partitioning coefficient estimation. The difference is most striking when comparing the placement of highly functionalized compounds (with more than three functional groups) based on ABSOLV-ppLFER and COSMOtherm predictions. The large $K_{\mathrm{W} / \mathrm{G}}$ values estimated by ABSOLVppLFERs lead to these compounds having a high affinity for aqueous aerosol. In contrast, predictions by COSMOtherm suggest that only very few of them (and not even the ones with the highest number of functional groups) prefer the aqueous aerosol phase; instead most of them have either gas or WIOM as the dominant phase. SPARC predicts a slightly larger preference of highly functionalized compounds for the aqueous phase than COSMOtherm.

In a cloud scenario with a much higher LWC (shown by the blue dotted boundary lines in Fig. 3), the choice of $K_{\mathrm{W} / \mathrm{G}}$ prediction method also matters. Whereas with ABSOLVppLFER and SPARC most of the highly functionalized compounds (i.e., 96 or $97 \%$ of the 736 compounds with more than three functional groups) partition into aqueous phase, only two-thirds $(64 \%)$ do so when the $K_{\text {W/G }}$ predicted by COSMOtherm are used. Further, only COSMOtherm predicts that some of the SOA compounds (circled in Fig. 3c) would prefer to form a separate WIOM phase rather than dissolve in the bulk aqueous phase. Those compounds are not sufficiently soluble in water to partition to the cloud and are not sufficiently volatile to be in the gas phase.

Table 2 summarizes the number and percentage of compounds that have dominant partitioning (at least $50 \%$ ) into different phases, which shows the impact of using different prediction techniques on phase distribution calculations in different atmospheric scenarios. In a parameterization of SOA formation that includes an aqueous aerosol phase, use of $K_{\mathrm{W} / \mathrm{G}}$ predicted by ABSOLV-ppLFERs (and probably also the commonly employed group contribution methods) would lead to much higher SOA mass than use of $K_{\mathrm{W} / \mathrm{G}}$ predicted by COSMOtherm. For instance, 10 and $17 \%$ of the compounds predominantly partition into the aqueous phase when predictions by SPARC and ABSOLV-ppLFER are used, in contrast to only 14 compounds (less than $1 \%$ ) with COSMOtherm predictions (Table 2 scenario a). A large difference also occurs in the cloud scenarios (Table 2 scenarios $b$ and d), where SPARC and ABSOLV-ppLFER predict twice as many compounds partitioning into the aqueous phase than COSMOtherm. Incidentally, in a parameterization of SOA formation that does not account for an aqueous aerosol phase (the scenario in Fig. S12c and Table 2 scenario c), the impact of the choice of partitioning prediction method is much smaller. The number of compounds on the 
Table 2. Percentage and number of compounds with at least $50 \%$ in gas, water, or WIOM phase under different aerosol and cloud scenarios predicted with SPARC, ABSOLV-ppLFER, and COSMOtherm. The four scenarios a-d correspond to the scenarios in Fig. S12a-d in the Supplement.

\begin{tabular}{|c|c|c|c|c|c|}
\hline \multirow[t]{2}{*}{ Aerosol scenarios } & \multicolumn{3}{|c|}{$\begin{array}{l}\text { (a) Aerosol with two separated phases } \\
\left(\mathrm{LWC}=10 \mu \mathrm{g} \mathrm{m}^{-3}, \mathrm{OM}=10 \mu \mathrm{g} \mathrm{m}^{-3}\right)\end{array}$} & \multicolumn{2}{|c|}{$\begin{array}{l}\text { (c) Aerosol without water phase } \\
\left(\mathrm{LWC}=0 \mu \mathrm{g} \mathrm{m}^{-3}, \mathrm{OM}=10 \mu \mathrm{g} \mathrm{m}^{-3}\right)\end{array}$} \\
\hline & $\Phi_{\mathrm{G}}>50 \%^{\mathrm{a}}$ & $\Phi_{\mathrm{W}}>50 \%^{\mathrm{a}}$ & $\Phi_{\text {WIOM }}>50 \%^{\mathrm{a}}$ & $\Phi_{\mathrm{G}}>50 \%$ & $\Phi_{\text {WIOM }}>50 \%$ \\
\hline SPARC & $85 \%(2892)^{b}$ & $10 \%(352)$ & $4 \%(134)$ & $92 \%(3132)$ & $8 \%(282)$ \\
\hline ABSOLV-ppLFER & $82 \%(2804)$ & $17 \%(570)$ & $1 \%$ & $96 \%$ & $4 \%(141)$ \\
\hline COSMOtherm & $96 \%(3268)$ & $0 \%(14)$ & $3 \%(119)$ & $96 \%(3282)$ & $4 \%(131)$ \\
\hline \multirow[t]{2}{*}{ Cloud scenarios } & \multicolumn{3}{|c|}{$\begin{array}{l}\text { (b) Cloud with WIOM phase } \\
\left(\mathrm{LWC}=0.3 \mathrm{~g} \mathrm{~m}^{-3}, \mathrm{OM}=10 \mu \mathrm{g} \mathrm{m}^{-3}\right)\end{array}$} & \multicolumn{2}{|c|}{$\begin{array}{l}\text { (d) Cloud without WIOM phase } \\
\left(\mathrm{LWC}=0.3 \mathrm{~g} \mathrm{~m}^{-3}, \mathrm{OM}=0 \mu \mathrm{g} \mathrm{m}^{-3}\right)\end{array}$} \\
\hline & $\Phi_{\mathrm{G}}>50 \%$ & $\Phi_{\mathrm{W}}>50 \%$ & $\Phi_{\mathrm{WIOM}}>50 \%$ & $\Phi_{\mathrm{G}}>50 \%$ & $\Phi_{\mathrm{W}}>50 \%$ \\
\hline SPARC & $36 \%(1242)$ & $64 \%(2168)$ & $0 \%(0)$ & $36 \%(1242)$ & $64 \%(2172)$ \\
\hline ABSOLV-ppLFER & $35 \%(1201)$ & $65 \%(2211)$ & $0 \%(0)$ & $35 \%(1203)$ & $65 \%(2211)$ \\
\hline COSMOtherm & $66 \%(2258)$ & $33 \%(1137)$ & $0 \%(9)$ & $66 \%(2267)$ & $34 \%(1147)$ \\
\hline
\end{tabular}

${ }^{\mathrm{a}} \Phi_{\mathrm{G}}, \Phi_{\mathrm{W}}$, and $\Phi_{\text {WIOM }}$ represent fractions of compounds in gas phase, water phase, and WIOM phase, respectively. ${ }^{\mathrm{b}}$ Number in brackets is number of compounds.

right side of the blue dotted boundary in Fig. S13 does not vary substantially with different predictions. Table $\mathrm{S} 1$ in the Supplement summarizes the number and percentage of compounds that change their partitioning between gas and condensed phase under different atmospheric conditions when a different prediction method is used. Depending on the scenarios, a total of 2.0 up to $34 \%$ of the 3414 compounds have a different dominant phase when using a different prediction method. This change is larger for the cloud scenarios and much lower for the aerosol scenarios especially if the aerosol contains no water.

\section{Conclusions}

For compounds implicated in SOA formation, the prediction of $K_{\mathrm{W} / \mathrm{G}}$ is much more uncertain than the prediction of $K_{\text {WIOM/G }}$. This is true even if we consider that $K_{\text {WIOM/G }}$ will vary somewhat depending on the composition of the WIOM (Wang et al., 2015). In particular, the methods currently used for $K_{\mathrm{W} / \mathrm{G}}$ prediction of these substances have the potential to greatly overestimate $K_{\text {W/G }}$. This uncertainty is consequential, as the predicted equilibrium phase distribution in the atmosphere, and therefore also the predicted aerosol yield, is very sensitive to the predicted values of $K_{\mathrm{W} / \mathrm{G}}$ : depending on the method used for prediction, the aqueous phase is either very important for SOA formation from the studied set of compounds or hardly at all. Isaacman-VanWertz et al. (2016) recently found the estimated phase distribution of 2-methylerythritol, an isoprene oxidation product (in Fig. S6 of Isaacman-VanWertz et al., 2016), to be highly dependent on the chosen method for predicting $K_{\mathrm{W} / \mathrm{G}}$. Here we show that this is a general issue potentially affecting a very large number of SOA compounds. In order to identify reliable prediction methods, it will be necessary to experimentally de- termine the phase distribution of highly functionalized, atmospherically relevant substances, whereby the focus should be on establishing their partitioning into aqueous aerosol.

Data availability. COSMO files for the 3414 organic compounds can be accessed by contacting the corresponding author.

\section{Information about the Supplement}

The Supplement contains figures and text mentioned in the paper, including detailed information on the organic compounds, e.g., SMILES, molecular formula, molecular weight, functional groups, $\mathrm{O}: \mathrm{C}$ ratios, predicted $K$ values, ABSOLV-predicted solute descriptors, COSMOthermpredicted vapor pressures, and activity coefficients in WIOM and water.

\section{The Supplement related to this article is available online at https://doi.org/10.5194/acp-17-7529-2017-supplement.}

Competing interests. The authors declare that they have no conflict of interest.

Acknowledgements. We acknowledge funding from the Natural Sciences and Engineering Research Council of Canada. Computations for the COSMO files in this study were performed on the General Purpose Cluster (GPC) supercomputer at the SciNet HPC Consortium. SciNet is funded by the Canada Foundation for Innovation under the auspices of Compute Canada; the Government of Ontario; Ontario Research Fund - Research Excellence; and the University of Toronto. 
Edited by: Annmarie Carlton

Reviewed by: two anonymous referees

\section{References}

ACD/Labs: Advanced Chemistry Development. Data sheet: Absolv prediction module. Toronto (Canada), cited 2 December 2016, available at: http://www.acdlabs.com/download/docs/datasheets/ datasheet_absolv.pdf (last access: 15 June 2017), 2016.

Arp, H. P. H. and Goss, K. U.: Ambient Gas/Particle Partitioning. 3. Estimating Partition Coefficients of Apolar, Polar, and Ionizable Organic Compounds by Their Molecular Structure, Environ. Sci. Technol., 43, 1923-1929, https://doi.org/10.1021/es8025165, 2009.

Arp, H. P. H., Schwarzenbach, R. P., and Goss, K. U.: Ambient gas/particle partitioning. 2: The influence of particle source and temperature on sorption to dry terrestrial aerosols, Environ. Sci. Technol., 42, 5951-5957, https://doi.org/10.1021/es703096p, 2008.

Barley, M. H. and McFiggans, G.: The critical assessment of vapour pressure estimation methods for use in modelling the formation of atmospheric organic aerosol, Atmos. Chem. Phys., 10, 749767, https://doi.org/10.5194/acp-10-749-2010, 2010.

Compernolle, S., Ceulemans, K., and Müller, J.-F.: EVAPORATION: a new vapour pressure estimation methodfor organic molecules including non-additivity and intramolecular interactions, Atmos. Chem. Phys., 11, 9431-9450, https://doi.org/10.5194/acp-11-9431-2011, 2011.

Endo, S. and Goss, K.-U.: Applications of polyparameter linear free energy relationships in environmental chemistry, Environ. Sci. Technol., 48, 12477-12491, 2014.

Endo, S., Pfennigsdorff, A., and Goss, K. U.: Salting-out effect in aqueous $\mathrm{NaCl}$ solutions: trends with size and polarity of solute molecules, Environ. Sci. Technol., 46, 1496-1503, https://doi.org/10.1021/es203183z, 2012.

Goss, K.-U.: Prediction of the Temperature Dependency of Henry's Law Constant using Poly-Parameter Linear Free Energy Relationships, Chemosphere, 64, 1369-1374, 2006.

Hallquist, M., Wenger, J. C., Baltensperger, U., Rudich, Y., Simpson, D., Claeys, M., Dommen, J., Donahue, N. M., George, C., Goldstein, A. H., Hamilton, J. F., Herrmann, H., Hoffmann, T., Iinuma, Y., Jang, M., Jenkin, M. E., Jimenez, J. L., Kiendler-Scharr, A., Maenhaut, W., McFiggans, G., Mentel, Th. F., Monod, A., Prévôt, A. S. H., Seinfeld, J. H., Surratt, J. D., Szmigielski, R., and Wildt, J.: The formation, properties and impact of secondary organic aerosol: current and emerging issues, Atmos. Chem. Phys., 9, 5155-5236, https://doi.org/10.5194/acp9-5155-2009, 2009.

Hilal, S. H., Karickhoff, S. W., and Carreira, L. A.: Prediction of the solubility, activity coefficient and liquid/liquid partition coefficient of organic compounds, Qsar Comb. Sci., 23, 709-720, 2004.

Hilal, S. H., Ayyampalayam, S. N., and Carreira, L. A.: Air-Liquid Partition Coefficient for a Diverse Set of Organic Compounds: Henry's Law Constant in Water and Hexadecane, Environ. Sci. Technol., 42, 9231-9236, https://doi.org/10.1021/es8005783, 2008.
Hodzic, A., Aumont, B., Knote, C., Lee-Taylor, J., Madronich, S., and Tyndall, G.: Volatility dependence of Henry's law constants of condensable organics: Application to estimate depositional loss of secondary organic aerosols, Geophys. Res. Lett., 41, 4795-4804, https://doi.org/10.1002/2014g1060649, 2014.

Ip, H. S. S., Huang, X. H. H., and Yu, J. Z.: Effective Henry's law constants of glyoxal, glyoxylic acid, and glycolic acid, Geophys. Res. Lett., 36, L01802, https://doi.org/10.1029/2008g1036212, 2009.

Isaacman-VanWertz, G., Yee, L. D., Kreisberg, N. M., Wernis, R., Moss, J. A., Hering, S. V., de Sá, S. S., Martin, S. T., Alexander, M. L., Palm, B. B., Hu, W., Campuzano-Jost, P., Day, D. A., Jimenez, J. L., Riva, M., Surratt, J. D., Viegas, J., Manzi, A., Edgerton, E., Baumann, K., Souza, R., Artaxo, P., and Goldstein, A. H.: Ambient Gas-Particle Partitioning of Tracers for Biogenic Oxidation, Environ. Sci. Technol., 50, 9952-9962, https://doi.org/10.1021/acs.est.6b01674, 2016.

Kalberer, M., Paulsen, D., Sax, M., Steinbacher, M., Dommen, J., Prevot, A. S. H., Fisseha, R., Weingartner, E., Frankevich, V., Zenobi, R., and Baltensperger, U.: Identification of polymers as major components of atmospheric organic aerosols, Science, 303, 1659-1662, https://doi.org/10.1126/science.1092185, 2004.

Klamt, A.: From Quantum Chemistry to Fluid Phase Thermodynamics and Drug Design, Elsevier, Amsterdam, the Netherlands, 2005.

Klamt, A. and Eckert, F.: COSMO-RS: a novel and efficient method for the a priori prediction of thermophysical data of liquids, Fluid Phase Equilibr., 172, 43-72, 2000.

Kroll, J. H., Donahue, N. M., Jimenez, J. L., Kessler, S. H., Canagaratna, M. R., Wilson, K. R., Altieri, K. E., Mazzoleni, L. R., Wozniak, A. S., Bluhm, H., Mysak, E. R., Smith, J. D., Kolb, C. E., and Worsnop, D. R.: Carbon oxidation state as a metric for describing the chemistry of atmospheric organic aerosol, Supplement, Nat. Chem., 3, 133-139, 2011.

Kurtén, T., Tiusanen, K., Roldin, P., Rissanen, M., Luy, J.-N., Boy, M., Ehn, M., and Donahue, N.: $\alpha$-Pinene autoxidation products may not have extremely low saturation vapor pressures despite high O:C ratios, J. Phys. Chem. A, 120, 2569-2582, https://doi.org/10.1021/acs.jpca.6b02196, 2016.

Loken, C., Gruner, D., Groer, L., Peltier, R., Bunn, N., Craig, M., Henriques, T., Dempsey, J., Yu, C.-H., Chen, J., Dursi, L. J., Chong, J., Northrup, S., Pinto, J., Knecht, N., and Van Zon, R.: SciNet: Lessons Learned from Building a Power-efficient Top-20 System and Data Centre, Journal of Physics: Conference Series, 256, 012026, https://doi.org/10.1088/1742-6596/256/1/012026, 2010.

McFiggans, G., Topping, D. O., and Barley, M. H.: The sensitivity of secondary organic aerosol component partitioning to the predictions of component properties - Part 1: A systematic evaluation of some available estimation techniques, Atmos. Chem. Phys., 10, 10255-10272, https://doi.org/10.5194/acp-10-102552010, 2010.

Mouchel-Vallon, C., Bräuer, P., Camredon, M., Valorso, R., Madronich, S., Herrmann, H., and Aumont, B.: Explicit modeling of volatile organic compounds partitioning in the atmospheric aqueous phase, Atmos. Chem. Phys., 13, 1023-1037, https://doi.org/10.5194/acp-13-1023-2013, 2013. 
Niederer, C. and Goss, K.-U.: Effect of ortho-chlorine substitution on the partition behavior of chlorophenols, Chemosphere, 71, 697-702, 2008.

Platts, J. A., Butina, D., Abraham, M. H., and Hersey, A.: Estimation of Molecular Linear Free Energy Relation Descriptors Using a Group Contribution Approach, J. Chem. Inf. Comput. Sci., 39, 835-845, 1999.

Raventos-Duran, T., Camredon, M., Valorso, R., Mouchel-Vallon, C., and Aumont, B.: Structure-activity relationships to estimate the effective Henry's law constants of organics of atmospheric interest, Atmos. Chem. Phys., 10, 7643-7654, https://doi.org/10.5194/acp-10-7643-2010, 2010.

Sander, R.: Compilation of Henry's law constants (version 4.0) for water as solvent, Atmos. Chem. Phys., 15, 4399-4981, https://doi.org/10.5194/acp-15-4399-2015, 2015.

Schröder, B., Fulem, M., and Martins, M. A. R.: Vapor pressure predictions of multi-functional oxygen-containing organic compounds with COSMO-RS, Atmos. Environ., 133, 135-144, https://doi.org/10.1016/j.atmosenv.2016.03.036, 2016.

US EPA: Estimation Programs Interface Suite ${ }^{\mathrm{TM}}$ for Microsoft ${ }^{\circledR}$ Windows, v 4.11 or insert version used. United States Environmental Protection Agency, Washington, DC, USA, 2012.

Valorso, R., Aumont, B., Camredon, M., Raventos-Duran, T., Mouchel-Vallon, C., Ng, N. L., Seinfeld, J. H., Lee-Taylor, J., and Madronich, S.: Explicit modelling of SOA formation from a-pinene photooxidation: sensitivity to vapour pressure estimation, Atmos. Chem. Phys., 11, 6895-6910, https://doi.org/10.5194/acp-11-6895-2011, 2011.

Wang, C., Lei, Y. D., Endo, S., and Wania, F.: Measuring and modeling the salting-out effect in ammonium sulfate solutions, Environ. Sci. Technol., 48, 13238-13245, https://doi.org/10.1021/es5035602, 2014
Wang, C., Goss, K.-U., Lei, Y. D., Abbatt, J. P. D., and Wania, F.: Calculating equilibrium phase distribution during the formation of secondary organic aerosol using COSMOtherm, Environ. Sci. Technol., 49, 8585-8594, https://doi.org/10.1021/acs.est.5b01584, 2015.

Wang, C., Lei, Y. D., and Wania, F.: Effect of Sodium Sulfate, Ammonium Chloride, Ammonium Nitrate, and Salt Mixtures on Aqueous Phase Partitioning of Organic Compounds, Environ. Sci. Technol., 50, 12742-12749, https://doi.org/10.1021/acs.est.6b03525, 2016.

Wania, F., Lei, Y. D., Wang, C., Abbatt, J. P. D., and Goss, K.U.: Novel methods for predicting gas-particle partitioning during the formation of secondary organic aerosol, Atmos. Chem. Phys., 14, 13189-13204, https://doi.org/10.5194/acp-14-131892014, 2014.

Wania, F., Lei, Y. D., Wang, C., Abbatt, J. P. D., and Goss, K.-U.: Using the chemical equilibrium partitioning space to explore factors influencing the phase distribution of compounds involved in secondary organic aerosol formation, Atmos. Chem. Phys., 15, 3395-3412, https://doi.org/10.5194/acp-15-3395-2015, 2015.

Waxman, E. M., Elm, J., Kurtén, T., Mikkelsen, K. V., Ziemann, P. J., and Volkamer, R.: Glyoxal and methylglyoxal setschenow salting constants in sulfate, nitrate, and chloride solutions: measurements and Gibbs energies, Environ. Sci. Technol., 49, 1150011508, https://doi.org/10.1021/acs.est.5b02782, 2015. 